\title{
Mass and number analysis of particles emitted during aircraft landing
}

\author{
Remigiusz Jasinski ${ }^{1, *}$ \\ ${ }^{1}$ Poznan University of Technology, Institute of Combustion Engine and Transport, Piotrowo Street 3, \\ 60-968 Poznan, Poland
}

\begin{abstract}
Particles are products of burning fossil fuels and the basic mechanisms of their formation are widely known. The above issue draws more and more attention of scientists due to the negative impact of solid particles on human health and climate. The emission of particles from aircraft is considered mainly in the case of near airport operations, which results from the applicable homologation regulations. However, due to the impact of exhaust emissions on the climate, it is planned to extend the regulations on limiting exhaust gases at cruising altitudes. The measurement of exhaust emissions in real flight conditions is very difficult to perform from a technical point of view, which is why modelling the environmental effects of air operations and laboratory measurements is very important. The article presents the results of jet engine tests made on the engine dynamometer and the measurements results of particle number concentration in the air during the landing of an aircraft equipped with the same engine as on the dynamometer.
\end{abstract}

\section{Introduction}

In the case of emissions from aircraft engines, particles are one of the main toxic exhaust components. In terms of their impact on the climate, the term of black carbon BC is used. Black carbon is a component of solid particles with the property of very strong absorption of light [1]. It is created as a result of incomplete combustion of fossil fuels, biofuels and biomass. In addition to its anthropogenic origin it can be also natural [2]. It is defined as a solid form of pure carbon absorbing solar radiation (light) in the entire wavelength range. Its formation always involves the emission of other solid particles and gaseous compounds such as nitrogen oxides and sulfur oxides. Black carbon causes the planet's warming and promotes the melting of glaciers by reducing the albedo (the ability to reflect sunlight directed to snow or ice).

It is assumed that the diameters of particles emitted by aircraft engines are not greater than $2.5 \mu \mathrm{m}$ and can be divided into primary and secondary particles. Primary solids consist of a non-volatile fraction of carbon (mainly black carbon) and other exhaust components that accumulate on the carbon core, using it as the nucleus of condensation. Primary particles include nitric and sulfuric acid, water and heavy hydrocarbons containing up to

\footnotetext{
* Corresponding author: remigiusz.w.jasinski@doctorate.put.poznan.pl
} 
30 carbon atoms. The diameters of the discussed particles reach values of several dozen nanometers [3].

The secondary particles are formed as a result of the reaction of the primary particles and other toxic components of the exhaust, such as nitrogen oxides, sulfur oxides and light hydrocarbons. The products of reactions on solid particles that can be found in the composition of secondary particles are: ammonium sulphate, ammonium nitrate and other compounds, mainly hydrocarbons. The resulting secondary particles are maintained in the air from several hours to several days, affecting the concentration of dust in areas adjacent to airports. The research indicates that as much as $70 \%$ of the solid particles emitted by aircraft engines is associated with the emission of nitrogen oxides, $14 \%$ are primary particles, $12 \%$ of solid particles are associated with sulfur oxides, and $4 \%$ are formed with hydrocarbons [4].

Exposure to particles results in an increased risk of cardiovascular and respiratory diseases and causes premature mortality. In the case of premature deaths, the dominant role is played by secondary solid particles, mainly produced on the basis of nitrogen and sulfur precursors [4]. Primary and hydrocarbon-related primary particles play a secondary role in this aspect. Many publications indicate that the emission of particles considerably in terms of negative health effects and far exceeds in this respect the emission of other toxic components of exhaust gases $[4,5,6]$.

The conventional approach to the emission of toxic compounds from aircraft engines assumes its control only in the phases of take-off, landing and taxiing of the aircraft [7]. The air operations which affect air quality, take place at an altitude of up to 3,000 feet. This is confirmed by the rules of aircraft engines certification (ICAO Annex 16), created with the aim of limiting exhaust emissions in areas adjacent to airports. Current research indicates, however, that emissions at cruising altitudes (above 3,000 feet) can be a significant part of total exhaust emissions affecting human health [8]. It may be that further research and future assessments of aviation impact on air quality will include a full emission of aircraft and its impact on the state of the atmosphere.

\section{Methodology of the research}

\subsection{Purpose and conditions of the research}

The aim of the conducted research was to analyze the emission of particles from the jet engine operating on the parameters corresponding to the landing of the aircraft and changes in the concentration of particles number in the air during the actual landing. Stationary tests were performed on the engine dynamometer during the service test. The research was conducted in 31st Tactical Aviation Base in Krzesiny in western Poland. Due to the fact that the research was conducted at military facility some details of the test object are confidential. Measurements of the particles concentration in the ambient air during the landing of the aircraft were carried out in the same military base approximately $1.5 \mathrm{~km}$ from the aircraft touchdown point. Meteorological conditions on the day of the measurements were characterized by lack of precipitation and wind speed of $10 \mathrm{~km} / \mathrm{h}$. 


\subsection{Test object and measuring apparatus}

The research object was Pratt \& Whitney engine, F100-PW-229 (Fig. 1). This engine is a drive of fighter aircraft F-16. Its maximum values of thrust are $79.13 \mathrm{kN}$ - without the use of afterburner, and $128.91 \mathrm{kN}$ with afterburner. It is a turbofan, twin-shaft engine with hydraulically adjustable nozzle. It is equipped with three-stage low pressure compressor and a ten-stage high pressure compressor. The combustion chamber is annular. Basic engine technical data are presented in the Table 1.

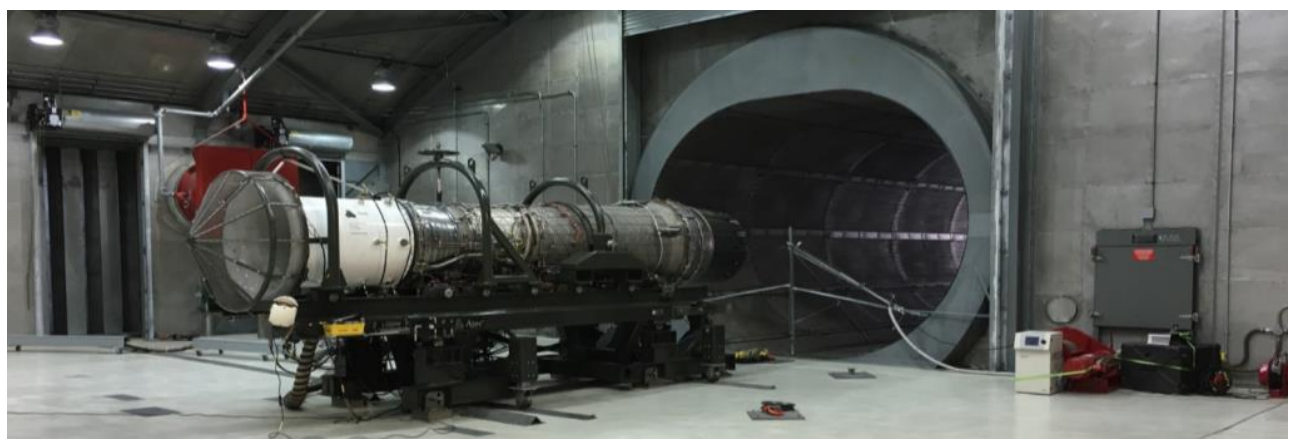

Fig. 1. The view of measuring stand with F100-PW-229 jet engine.

Table 1. Technical data of F100-PW-229 jet engine.

\begin{tabular}{|l|c|}
\hline \multicolumn{1}{|c|}{ Parameter } & F100-PW-229 \\
\hline Maximum thrust $[\mathrm{kN}]$ & 73.13 \\
\hline Length [mm] & 4855 \\
\hline Weight [kg] & 1370 \\
\hline Specific fuel consumption $[\mathrm{kg} /(\mathrm{kG} \mathrm{h})]$ & 0.693 \\
\hline Specific fuel consumption with afterburner $[\mathrm{kg} /(\mathrm{kG} \mathrm{h})]$ & 2.6 \\
\hline
\end{tabular}

The measurements of the concentration of particles in the air were made during the landing of the F-16 fighter (Fig. 2b). The measuring apparatus was set up in the approach axis for the landing of the aircraft (Fig. 2a).

a)

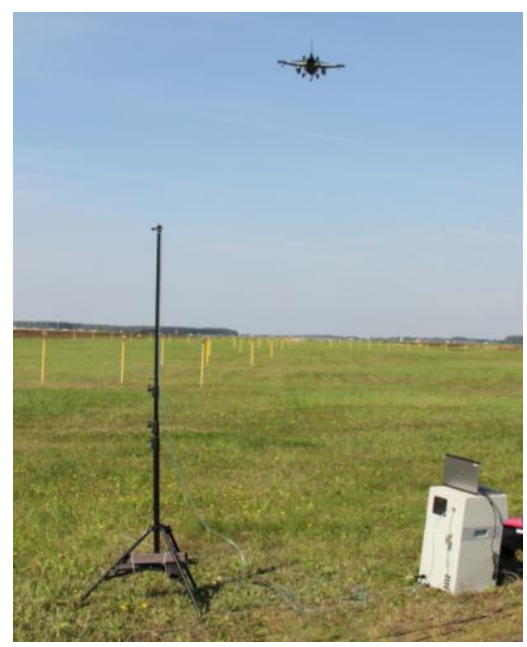

b)

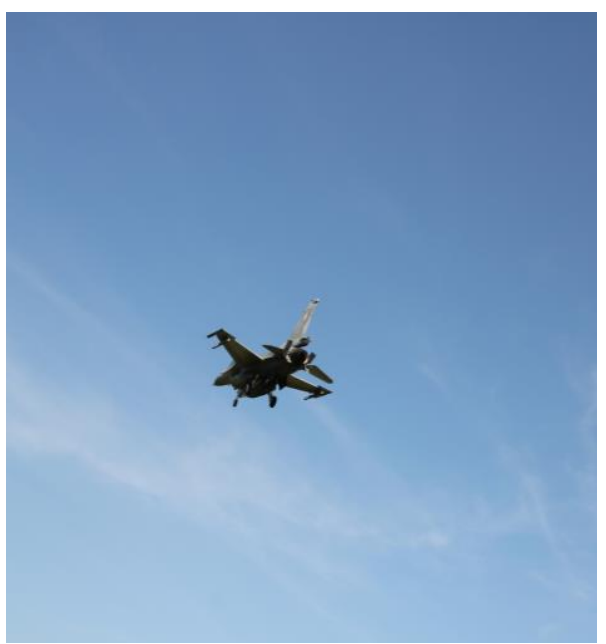

Fig. 2. Position of measuring apparatus (a) and F-16 fighter (b). 
The measurements were divided into three phases: pre-landing measurement - to determine the measurement background; measurement during the landing - to determine changes in the concentration of particles during the landing operation; measurement after landing - to determine the maximum concentration of particles. Measurements of the concentration of particles in the ambient air during the landing of the fighter were made 8 times. Landings were made at $15 \%$ throttle opening. The same parameters of the engine were set up during engine dynamometer measurements. The descent angle was about the standard $3^{\circ}$.

Measurement of particle diameters was performed with an EEPS 3090 (engine exhaust particle sizer ${ }^{\mathrm{TM}}$ ) (Fig. 3a). It enabled the measurement of a discrete range of particle diameters (from $5.6 \mathrm{~nm}$ to $560 \mathrm{~nm}$ ) on the basis of their differing speeds. The degree of electric mobility of particulate matter is changed exponentially, and measurement of their size is carried out at a frequency of $10 \mathrm{~Hz}$.

The sample routed through a dilution system and to the spectrometer while maintaining at the desired temperature. The initial filter retains particles with a diameter greater than 1 micron, which are outside of the measuring range of the device. After passing through the neutralizer the particles are directed to the charging electrode; after getting electrically charged they can be classed by their size. The particles deflected by the high-voltage electrode go to an annular slit, which is the space between the two cylinders. The gap is surrounded by a stream of clean air supplied from outside. Exhaust cylinder is built in a stack of sensitive electrodes isolated from one another and arranged in a ring. The electric field present between the cylinders causes the repulsion of particles from the positively charged electrode; then the particles are collected on the outer electrodes. When striking the electrodes, the particles generate an electric current, which is read by a processing circuit.

In addition, the Semtech DS gas analyzer was used (Fig. 3b). The above apparatus is used to measure the concentration of harmful gaseous exhaust gas compounds. It allows, however, to additionally determine the excess air coefficient, which allowed to perform additional calculations to determine the exhaust mass flow.

a)

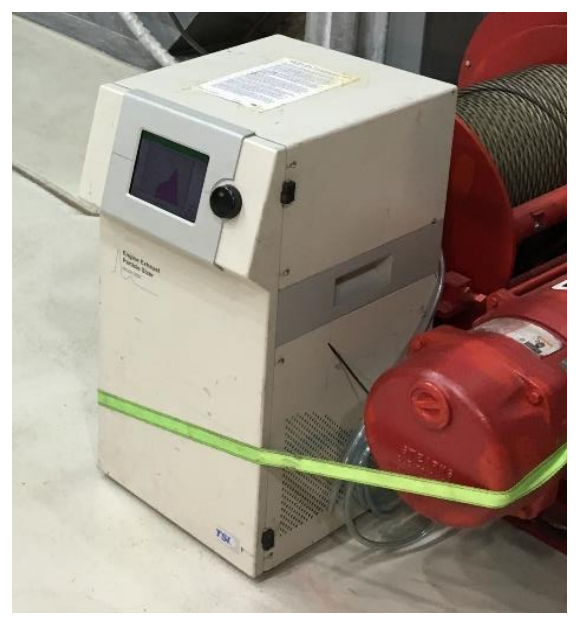

b)

Fig. 3. The view of measuring apparatus - EEPS 3090 (a) and Semtech DS (b). 


\section{Research results and their analysis}

To perform measurements on the engine test bench for the engine parameters corresponding to the landing, it is necessary to set these parameters. Due to the above fact, a research flight was conducted during which the flight recorders recorded the basic flight parameters and the operation of the propulsion system. On this basis, the range of the relative rotational speed of the fan and the thrust force was determined as characteristic values for landing operation. The operating points of the engine during flight are shown in Figure 4. Based on the information from the recorders, it was determined that the landing operation is characterized by the relative rotational speed of the fan at $60-85 \%$ and the relative thrust of $30-80 \%$.

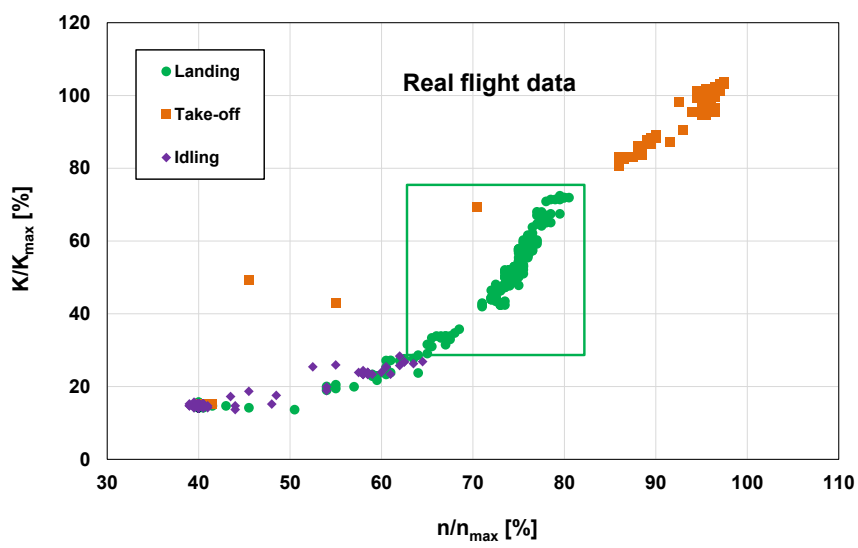

Fig. 4. Engine parameter data during the actual flight.

For determined values of engine parameters, the number concentration of particles and their dimensional distribution were measured. The average size distribution of particles is shown in the Figure 5a. The dominant particles are from 6 to $15 \mathrm{~nm}$. This is a characteristic dimensional distribution of particles for aircraft engines. Particles with these diameters are at the measurement limit. In spite of their very large number, they are invisible to the human eye, therefore they do not pose a threat. The fact is that they are the most dangerous to human health. Whereas the variable density of the particles according to their diameter, the mass distribution of particles was determined (Fig. 5b).

a)

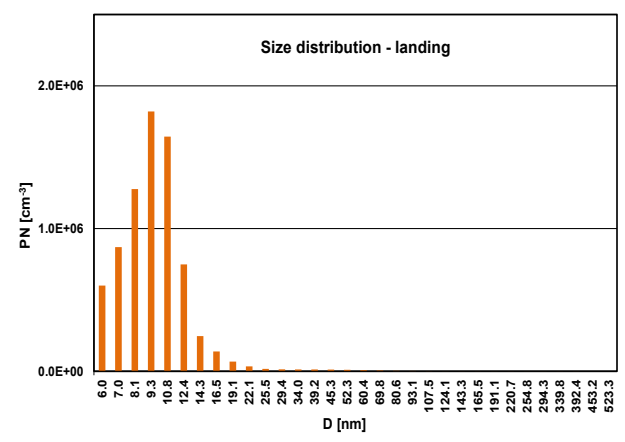

b)

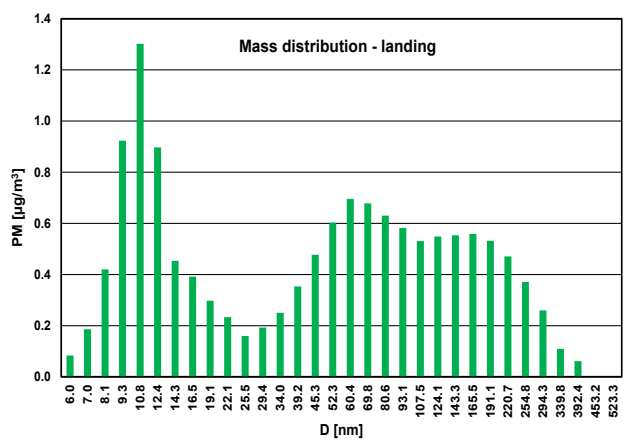

Fig. 5. Size (a) and mass distribution (b) obtained during stationary measurements. 
The very small number of particles with diameters above $40 \mathrm{~nm}$ (not visible on the size distribution due to their very small share) is a significant part of the total mass distribution. Due to the above fact, a deeper analysis of the result is presented in the Figure 6. Shares of particles with specific diameter in total mass of particles in the exhaust volume were determined. It was found that only $1 \%$ of the total number of particles is responsible for $60 \%$ of their total mass. The above fact indicates the necessity of making very accurate measurements, in particular when their mass is determined on the basis of the measurement of the number of particles. In addition, it is worth noting that despite the very large number of emitted particles their mass is very small. However, air quality is determined on the basis of the mass, so in relation to the existing regulations a large number of small particles is not a threat, which is not true.

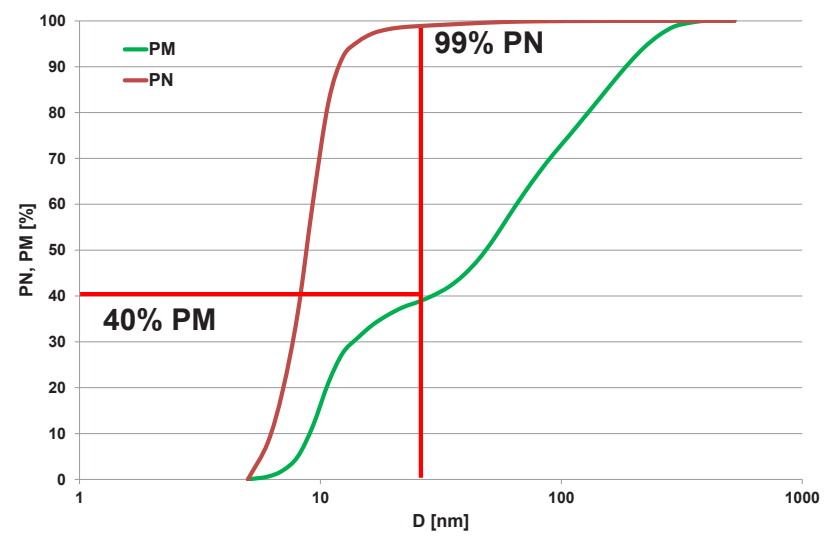

Fig. 6. The proportion of the particles number in the emitted mass.

The results of measurements carried out during the actual landing of aircraft are shown in Figure 7. For all six landing attempts, the size distribution of particles in the air ambient took on a similar shape. Particles with a diameter of 5-15 nm dominate, just like in the size distribution obtained on the engine dynamometer. Obtained results from the dynamometer and measurements in the ambient air differ in the concentration of particles with particular diameter values. This is due to the fact that the exhaust fuses are diluted by the ambient air in the case of a real landing. Particularly important is the repeatability of the results obtained during the ambient air measurements. The resulting size distributions do not differ by the share of individual particles in the total number, but only their concentration in the air, which results from the different degree of exhaust gas dilution.

a)

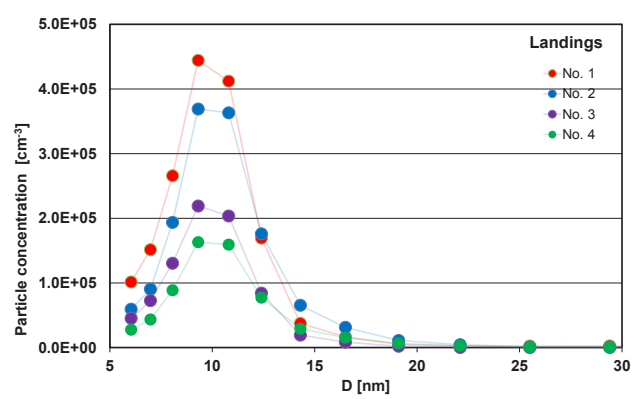

b)

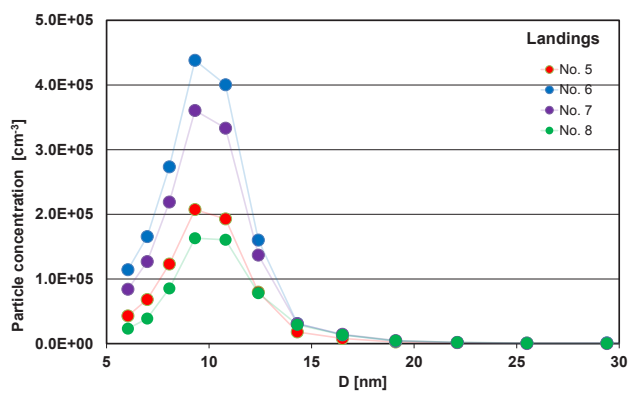

Fig. 7. Particle size distributions obtained during 1-4 (a) and 5-8 (b) landing. 


\section{Summary}

On the basis of the research carried out, it was concluded that in the case of particles emitted from a jet engine during landing, particles from the range of 6-15 nm are dominant. In the case of mass analysis, particular attention should be paid to a small group of particles with diameters greater than $50 \mathrm{~nm}$, because they are the main source of mass emissions. In addition, they do not significantly affect the mass concentration of particles in the ambient air, which in accordance with current regulations do not cause deterioration of air quality. In addition, they do not significantly affect the mass concentration of particles in the ambient air, which in accordance with current regulations do not cause deterioration of air quality. The above fact indicates the necessity to extend the air quality assessment by measuring the number of particles.

Particles size distributions obtained during real landing operations do not differ from the distributions obtained on the engine dynamometer. The main difference between the results obtained in the laboratory and the results of measurements during the actual airport operation is the concentration of particles. Naturally, higher concentrations were obtained when measurements were taken immediately after the nozzle of the jet engine. The concentration of particles in the ambient air is relatively smaller due to the dilution of exhaust gases and the dispersion of particles.

\section{References}

1. Report to Congress on black carbon, black carbon and its effects on climate, Chapter 2

2. W. Gis, J. Pielecha, J. Waśkiewicz, M. Gis, M. Menes, IOP Conf. Series: Materials Science and Engineering, 148 (2016)

3. R. Jasinski, Matec Web Conf., 118 (2017)

4. E. Brunelle-Yeung, The impacts of aviation emissions on human health through changes in air quality and UV irradiance, Masters of science thesis, Department of Aeronautics and Astronautics, Massachusetts Institute of Technology, Cambridge, 2009

5. J. Rojo, Future trends in local air quality impacts of aviation, S.M. thesis, Department of Aeronautics and Astronautics, Massachu-setts Institute of Technology, Cambridge, 2007

6. P. Watkiss, S. Holland, Baseline scenarios for service-contract for carrying out cost benefits analysis of air quality related issues, in particular in the clean air for Europe (CAFE) program, 2005

7. J. Markowski, M. Kazimierczak, P. Benedict, D. Olejniczak, Matec Web Conf., 118 (2017)

8. US FAA, Environmental tool suite frequently asked questions 